\section{Laterally coupled DFB interband cascade laser with tapered ridge}

\author{
S. Becker, J. Scheuermann, R. Weih, L. Nähle, O. König, \\ M. Fischer, J. Koeth, S. Höfling, and M. Kamp
}

In this work, single-mode distributed feedback interband cascade lasers with tapered ridges are presented. The lasers consists of a $500 \mu \mathrm{m}$ long and $5.7 \mu \mathrm{m}$ wide ridge wave guide section followed by a $1400 \mu \mathrm{m}$ long tapered section with an output facet width of $35 \mu \mathrm{m}$. The device is operational in continuous wave mode and well above room temperature. At $25^{\circ} \mathrm{C}$, the threshold current and threshold current density were $81 \mathrm{~mA}$ and $324 \mathrm{~A} / \mathrm{cm}^{2}$, respectively. We demonstrate a tuning range of over $14 \mathrm{~nm}$ with side mode suppression ratios larger than $25 \mathrm{~dB}$. The device showed temperature and injection power tuning coefficients of $0,35 \mathrm{~nm} / \mathrm{K}$ and $4.09 \mathrm{~nm} / \mathrm{W}$, respectively. Output powers of $18 \mathrm{~mW}$ single mode and $35 \mathrm{~mW}$ multimode were achieved.

Introduction: Distributed feedback (DFB) interband cascade lasers (ICLs) are especially interesting for applications in tunable laser absorption spectroscopy (TLAS) in the mid-infrared (MIR) spectral range from 3-6 $\mu \mathrm{m}$ [1-7]. Due to their low power consumption and compactness ICLs are beneficial for various fields from industrial [8] to medical sector [9]. Besides the ICL there are two other types of semiconductor DFB-lasers [10] which also access the $3 \mu \mathrm{m}$ region in cwoperation near room temperature, diode lasers based on $\mathrm{GaSb}$ utilizing type-I interband-transitions [11] and Quantum cascade lasers [12] using intraband transitions. Diode lasers approach the 3-4 $\mu \mathrm{m}$ region from smaller wavelength and are limited in their output power in this region because they lack appropriate material systems and suffer from high Auger-recombination as well as limited inclusion potential in the valence band. Quantum cascade lasers converge to this region from larger wavelength, they are limited by carrier confinement in the active quantum wells. Despite their huge development in recent years, the energy consumption of quantum cascade lasers is still high compared to interband cascade lasers. Therefore, ICLs are more suitable for in field applications. For various purposes it is advantageous to couple light into optical fibers. To couple directly without additional optics, a low beam divergence is essential for good coupling efficiencies and hence higher output power. ICLs with tapered ridges for high-power and highbrightness were recently published [13]. Nevertheless these devices are not suitable for TLAS due to their multi mode spectrum.

Single-mode ICLs with high output power and small farfield are therefore of considerable interest to expand the application field of ICLs. Commonly used ICLs for TLAS are DFB ridge-waveguide semiconductor lasers [14] with limited output power and a relatively large farfield angle in slow and fast axis.

Growth and Fabrication: The laser structure was grown as described in [15], with minor changes to the design in order to reach the appropriate wavelength on a Te-doped GaSb-substrate by molecular beam epitaxy. The active region consists of 5 stages and it has a thickness of $232 \mathrm{~nm}$. To guide the optical mode the active region was embedded into $340 \mathrm{~nm}$ thick GaSb separate confinement layers. The lower and upper super lattice claddings consist of short period AlSb/InAs superlattices with total thicknesses of $2565 \mathrm{~nm}$ and $1700 \mathrm{~nm}$, respectively.

The laser is formed by a $5.7 \mu \mathrm{m}$ wide and $500 \mu \mathrm{m}$ long ridge wave guide section followed by a $1400 \mu \mathrm{m}$ long tapered section with an output facet width of $35 \mu \mathrm{m}$. The structure was defined by electron beam lithography and etched through the active core by a chlorine/argon plasma base reactive ion etch process. Lateral chrome gratings were defined by electron beam lithography at the ridge waveguide section to achieve longitudinal mode selection [14]. For passivation $\mathrm{Si}_{3} \mathrm{~N}_{4}$ and $\mathrm{SiO}_{2}$ layers were applied. A contact window was etched through the passivation on top of the ridge waveguide section as well as the tapered section based on $\mathrm{CHF}_{3}$ plasma base reactive ion etching. For current injection a TiPtAu - top metallization layer was deposited. Subsequently a $11 \mu \mathrm{m}$ thick Au layer was electroplated. After thinning the substrate to $150 \mu \mathrm{m}$, the bottom contact was deposited. The sample was cleaved into bars with $1.9 \mathrm{~mm}$ long cavities. To suppress the amplification of higher lateral modes in the tapered section an antireflection coating consisting of a single layer of $485 \mathrm{~nm} \mathrm{Al}_{2} \mathrm{O}_{3}$ reduced the reflection of the front facet to approximately $5 \%$. The back facet was passivated and metal coated for high reflection. After the laser chips were soldered epitaxial-sidedown on a C-mount heat spreader, the device was analyzed with respect to temperature dependent spectral properties, L-I-V characteristics as well as the corresponding horizontal farfield.

Results: The ICL with tapered ridge shows output powers of up to $18 \mathrm{~mW}$ mono mode (straight line) and $35 \mathrm{~mW}$ multi mode (dashed line) in $\mathrm{cw}$ mode. Figure 1 shows the $\mathrm{L}-\mathrm{I}-\mathrm{V}$ characteristics at different temperatures. At $25^{\circ} \mathrm{C}$ the threshold current density is $324 \mathrm{~A} / \mathrm{cm}^{2}$ and the threshold current $81 \mathrm{~mA}$.

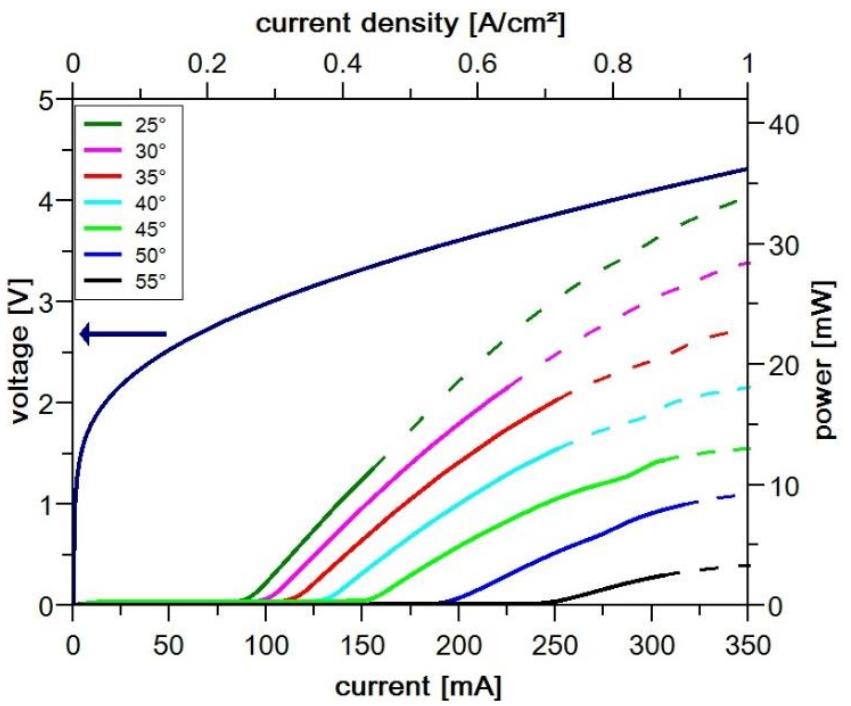

Fig. 1: Electro-optical characteristics at different heatsink temperatures of the coated ICL device mounted epi side down on a C-mount, Straight lines: single mode operation, dashed lines: multi mode operation.

In Figure 2, the spectrum of the device at $25^{\circ} \mathrm{C}$ and a current of $100 \mathrm{~mA}$ as well as at $55^{\circ} \mathrm{C}$ and a current of $310 \mathrm{~mA}$, yielding side mode suppression ratios $>25 \mathrm{~dB}$, are observed. The linewidth is limited by the fourier-transform infrared spectrometer resolution of $0.125 \mathrm{~cm}^{-1}$.

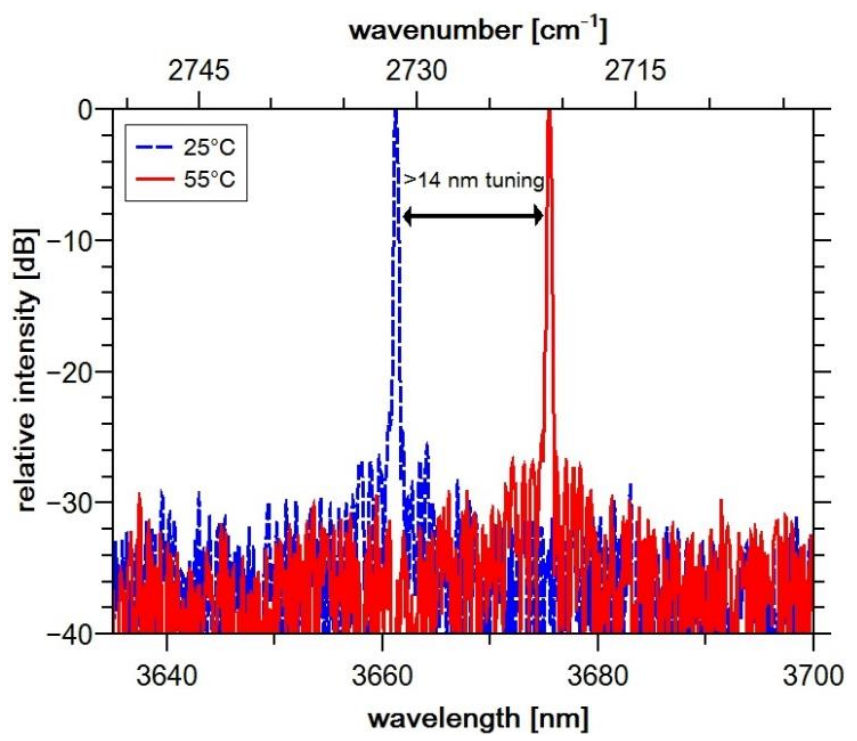

Fig. 2: Spectral characteristic of the device at $25^{\circ} \mathrm{C}$ and $55^{\circ} \mathrm{C}$ heatsink temperature, with $>25 \mathrm{~dB}$ SMSR and $>14 \mathrm{~nm}$ tuning range.

The general tuning characteristic is presented in Figure 3, with heatsink temperatures ranging from $25^{\circ} \mathrm{C}$ to $55^{\circ} \mathrm{C}$. A Fabry-Perot mode hop is observed at $45^{\circ} \mathrm{C}$ and $50^{\circ} \mathrm{C}$. The tuning coefficients were $0.35 \mathrm{~nm} / \mathrm{K}$, $0.022 \mathrm{~nm} / \mathrm{mA}$ and $4.09 \mathrm{~nm} / \mathrm{W}$ for temperature, current and injection power, respectively. An overall tuning range of $>14 \mathrm{~nm}$ was achieved utilizing current and temperature tuning. 


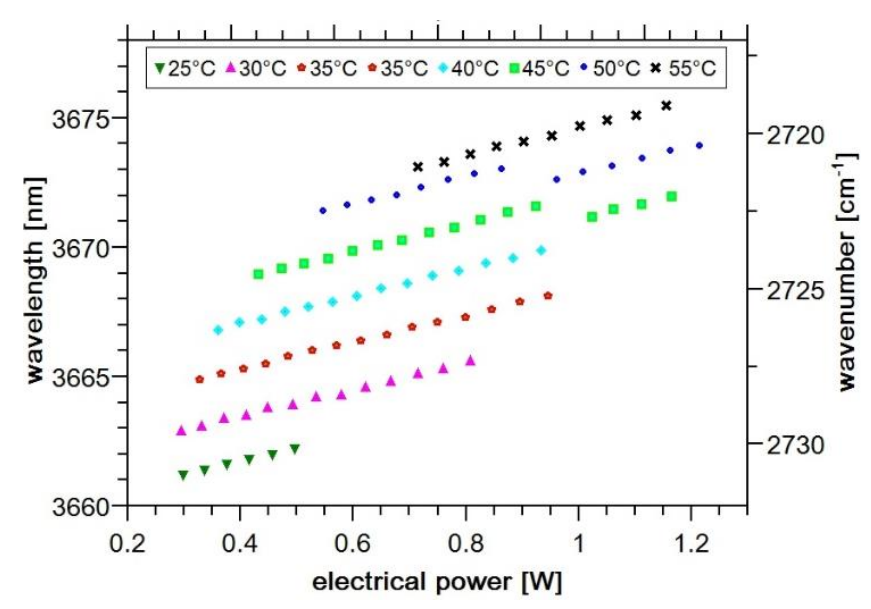

Fig. 3: Wavelength shift at heatsink temperatures from $25^{\circ} \mathrm{C}$ to $55^{\circ} \mathrm{C}$, as a function of injected electrical power, a Fabry-Perot mode hop occurred at $45^{\circ} \mathrm{C}$ and $50^{\circ} \mathrm{C}$.

The corresponding farfield in slow axis at $35^{\circ} \mathrm{C}$ heatsink temperature and $200 \mathrm{~mA}$ injection current is given in Figure 4, with a FWHM of $7.4^{\circ}$ and a $1 / \mathrm{e}^{2}$-width of $12.5^{\circ}$.

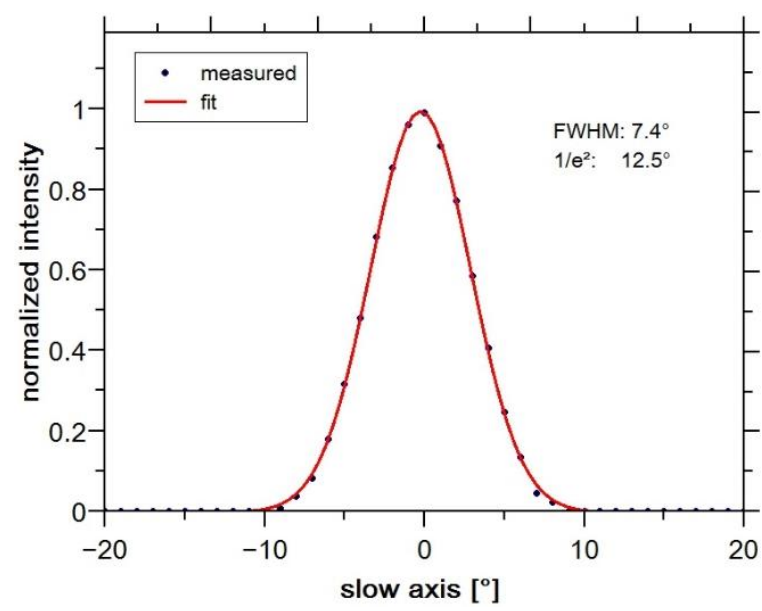

Fig. 4: Farfield angle in slow axis at $35^{\circ} \mathrm{C}$ heatsink temperature and at $200 \mathrm{~mA}$ injection current, FWHM of $7.4^{\circ}$ and $1 / e^{2}$-width of $12.5^{\circ}$.

Due to high coupling losses for direct coupling into mid-infrared fibers on one hand and the need for low power consumption for battery powered applications on the other hand, we focused on a suitable balance between high output power, small farfield and low power consumption.

Conclusion: We presented the first DFB ICL with tapered ridges. The ICL was operated in $\mathrm{cw}$ mode at room temperature with small farfield width of $7.4^{\circ} \mathrm{FWHM}$ and high output power for efficient direct fiber coupling, side mode suppression ratio of $>25 \mathrm{~dB}$ as well as $>14 \mathrm{~nm}$ tuning range. Single mode operation was observed up to a heatsink temperature of $55^{\circ} \mathrm{C}$.

Acknowledgment: Financial support by the German Federal Ministry of Education and Research in terms of the APOSEMA project (contract no: 13N13083) within the funding program Photonics Research Germany is gratefully acknowledged.

S. Becker, J. Scheuermann, R. Weih, L. Nähle, O. König, M. Fischer and J. Koeth: nanoplus Nanosystems and Technologies $\mathrm{GmbH}$, Oberer Kirschberg 4, Gerbrunn D-97218, Germany

E-mail: steffen.becker@nanoplus.com
S. Höfling: Technische Physik, Physikalisches Institut and Wilhelm Conrad Röntgen-Research Center for Complex Material Systems, Universität Würzburg, Am Hubland D-97074 Würzburg, Germany

S. Höfling also with School of Physics and Astronomy, North Haugh, St. Andrews KY16 9SS, United Kingdom

M. Kamp: Physikalisches Institut and Wilhelm Conrad RöntgenResearch Center for Complex Material Systems, Universität Würzburg, Am Hubland D-97074 Würzburg, Germany

\section{References}

[1] Miller, J.H., Bakhirkin, Y.A., Ajtai, T., Tittel, F.K., Hill, C.J. and Yang, R.Q.: 'Detection of formaldehyde using off-axis integrated cavity output spectroscopy with an interband cascade laser', Appl. Phys. B, 2006, 85, (391), doi: 10.1007/s00340-006-2310-2

[2] Lundqvist, S., Kluczynski, P., Weih, R., Edlinger, M.v., Nähle, L., Fischer, M., Bauer, A., Höfling, S. and Koeth, J.: 'Sensing of formaldehyde using a distributed feedback interband cascade laser emitting around 3493 nm', Appl. Opt., 2012, 51, (6009), doi: 10.1364/AO.51.006009

[3] Kluczynski, P. and Lundqvist, S.: 'Method and apparatus for remote detecton of alcohol vapor in the atmosphere', U.S. Patent Application, 2013, 13/901,260

[4] Wysocki, G., Bakhirkin, Y., So, S., Tittel, F.K., Hill, C.J., Yang, R.Q. and Fraser, M.P.: 'Dual interband cascade laser based tracegas sensor for environmental monitoring', Appl. Opt., 2007, 46, (8202), doi: 10.1364/AO.46.008202

[5] Vurgaftman, I., Weih, R., Kamp, M., Meyer, J.R., Canedy, C.L., Kim, C.S., Kim, M., Bewely, W.W., Merritt, C.D., Abell, J. and Höfling, S.: 'Interband cascade lasers', J. Phys. D, 2015, 48, (123001) doi: 10.1088/0022-3727/48/12/123001

[6] Li, C., Dong, L., Zheng, C. and Tittel, F.K.: 'Compact TDLAS based optical sensor for ppb-level ethane detection by use of a $3.34 \mu \mathrm{m}$ room-temperature CW interband cascade laser', Sensor. Actuat. Biol. Chem, 2016, 232, pp. 188-194, doi: 10.1016/j.snb.2016.03.141

[7] Yang, R.Q.: 'Infrared laser based on intersubband transitions in quantum wells', Superlatt. Microstruct., 1995, 17, pp. 77-83

[8] da Silva, I.J.G., Tütüncü, E., Nägele, M., Fuchs, P., Fischer, M., Raimundo, I.M. and Mizaikoff, B.: 'Sensing hydrocarbons with interband cascade lasers and substrate-integrated hollow waveguides', Analyst, 2016, 141, pp. 4432-4437, doi: 10.1039/C6AN00679E

[9] Ren, W., Luo, K., Cao, Y., Jiang, W. and Tittel, F.K.: 'Interband cascade laser based absorption sensor for ppb-level formaldehyde detection', Proc. SPIE, 2015, 9370, doi: 10.1117/12.2083715

[10] Bauer, A., Rößner, K., Lehnhardt, T., Kamp, M., Höfling, S., Worschech, L. and Forchel, A.: 'Mid-infrared semiconductor heterostructure lasers for gas sensing applications', Semicond. Sci. Technol., 2010, 26, (014032)

[11] Nähle, L., Belhasene, S., Edlinger, M.v., Fischer, M., Boissier, G., Grech, P., Narcy, G., Vicet, A., Rouillard, Y., Koeth, J. and Worschech, L.: 'Continuous-wave operation of type-I quantum well DFB laser diodes emitting in $3.4 \mu \mathrm{m}$ wavelength range around room temperature', Elec. Lett., 2011, 47, (11704739), doi: 10.1049/el.2010.2733

[12] Wolf, J.M., Riedi, S., Süess, M.J., Beck, M. and Faist, J.: '3.36 um single-mode quantum cascade laser with a dissipation below 250 mW', Opt. Expr., 2016, 24, (254097), doi:10.1364/OE.24.000662

[13] Bewley, W.W., Kim, C.S., Canedy, C.K., Merritt, C.D., Vurgaftman, I., Abell, J., Meyer, J.R., Kim, M.: 'High-Power, highbrightness continuous-wave interband cascade lasers with tapered ridges', Appl. Phys. Lett., 2013, 103, (111111), doi: 10.1063/1.4821263 [14] Weih, R., Nähle, L., Höfling, S., Koeth, J. and Kamp, M.: 'Single mode interband cascade laers based on lateral metal gratings', Appl. Phys. Lett., 2014, 105, (071111), doi: 10.1063/1.4893788

[15] Weih, R., Kamp, M., Höfling, S.: 'Interband cascade laers with room temperature threshold current densities below $100 \mathrm{~A} / \mathrm{cm}^{\prime}$ ', Appl. Phys. Lett., 2013, 102, (231123), doi: 10.1063/1.4811133 